OPEN ACCESS

Edited by:

Yang Zhou,

Shenzhen University, China

Reviewed by:

Lirong Liu,

University of Surrey, United Kingdom

Martin Schoch,

King Mongkut's University of Technology Thonburi, Thailand

${ }^{*}$ Correspondence:

Daphne Gondhalekar

d.gondhalekar@tum.de

Specialty section:

This article was submitted to Urban Resource Management, a section of the journal

Frontiers in Sustainable Cities

Received: 01 August 2021 Accepted: 25 November 2021 Published: 17 December 2021

Citation:

Gondhalekar D and Erlbeck R (2021) Application of the Nexus Approach as an Integrated Urban Planning Framework: From Theory to Practice and Back Again.

Front. Sustain. Cities 3:751682 doi: $10.3389 /$ frsc. 2021.751682

\section{Application of the Nexus Approach as an Integrated Urban Planning Framework: From Theory to Practice and Back Again}

\author{
Daphne Gondhalekar ${ }^{1 *}$ and Ruth Erlbeck ${ }^{2}$ \\ ${ }^{1}$ Chair of Urban Water Systems Engineering, Department of Civil and Environmental Engineering, Technical University of \\ Munich (TUM), Munich, Germany, ${ }^{2}$ German International Cooperation (GIZ), Bonn, Germany
}

Urbanization has created some of the world's greatest development challenges. At the same time, cities present an opportunity to tackle these challenges comprehensively. For this, an integrated urban development approach is needed. The Water-Energy-Food (WEF) Nexus approach offers cities an integrated urban planning framework to devise sustainability pathways. However, so far there exist no comprehensive guidelines to aid municipal government decision-making on how to apply the Nexus approach in an urban context. This paper highlights the origins of the WEF Nexus approach within the integrated urban planning discourse. It explains the method to introduce Nexus with special emphasis on Nexus training supporting the implementation of the Nexus approach. The "Urban Nexus Development Cycle" as part of the Nexus training, guiding urban practitioners to overcome "silo thinking" is the innovative element as well as the pro-active involvement of universities in the Nexus process.

Keywords: integrated urban planning, Water-Energy-Food (WEF) Nexus, urban resilience, climate change, SDGs

\section{INTRODUCTION TO THE CONCEPT OF INTEGRATED URBAN PLANNING}

Urbanization has created some of the world's greatest development challenges. Although the world's cities occupy only $3 \%$ of the global land mass, they are responsible for $60-80 \%$ of the global energy consumption and $75 \%$ of global carbon emissions (UN, 2021). Most of the world's businesses and enterprises are located in cities, which currently generate roughly $80 \%$ of global GDP. Cities provide markets for industry and employment, foster technological innovations, and support high-density habitation and efficient land use, and a very high density of infrastructures and services.

Globally, over $50 \%$ of the population lives in urban areas today. By 2045, the world's urban population will increase by 1.5 times to 6 billion (World Bank, 2020). Metropolises in developing economy countries are often characterized by extreme poverty, unemployment and socio-economic disparities, unsustainable patterns of consumption and production, and are key contributors to climate change and environmental degradation. These cities face significant urban development challenges in terms of liveability, social inclusion, local economic development, access to urban basic services, mobility and climate change mitigation and adaptation. City leaders must move quickly to plan for growth and provide the basic services, infrastructure, and affordable housing for their expanding populations. Considering climate change and the goal to reach sustainable, environmentally friendly infrastructure solutions, a cross-sectoral approach is required 
(World Bank, 2020). If it remains unchecked, climate change will push 132 million people into poverty over the next 10 years, undoing hard-won development gains (World Bank, 2021).

Cities play an increasingly important role in tackling climate change, because their exposure to climate and disaster risk increases as they grow. Almost half a billion urban residents live in coastal areas, increasing their vulnerability to storm surges and sea level rise. In the 136 biggest coastal cities, there are 100 million people-or $20 \%$ of their population-and $\$ 4.7$ trillion in assets exposed to coastal floods (World Bank, 2020). Cities in developed countries like Europe are also increasingly facing these challenges, as well as new challenges like slowing economic growth, aging populations, growing income disparities, social and spatial segregation, and ecosystems under pressure (EU, 2011). Nonetheless, cities will be home to the vast majority of the world population.

Hence, worldwide cities need to implement transformative approaches to achieve the Sustainable Development Goal (SDG) 11: to make cities inclusive, safe, resilient and sustainable (United Nations General Assembly, 2015) and climate friendly (BMUB/BMZ, 2015). The world needs a "new vision for urbanization," and Habitat III is a historic opportunity for the formulation of such a vision, during the critical first year of implementing the 2030 Agenda for Sustainable Development (United Nations, 2016).

To address these challenges, an integrated urban development approach is needed, a concept which dates back almost 100 years and has gained momentum in the last decades. The International Congress on Modern Architecture (CIAM), founded in 1924 (Mumford, 2000), identified challenges cities are facing holistically by describing different urban sectors related to the core functions work, dwelling, recreation and transport in a comparative format, to be able to compare cities worldwide. However, after the group disbanded (Mumford, 2000) a comparable approach has not developed. In the 1960's and 1970's, the increase in computing capacity enabled attempts to model cities holistically as complex systems, but these approaches remained very theoretical (DST, 2013).

Since the 1990's, there has been a renaissance of integrated strategic concepts for cities and urban regions (DST, 2013) which has continually developed in Germany as follows: in 1991 the Expert Committee on Urban Development Planning of the Association of German Cities pushed the concept of integrated urban development planning in its position papers, and in 2007, during the German EU Presidency, integrated urban development was framed in the Leipzig Charter as a prerequisite for successful urban sustainability. From 2010, concerns about climate change impacts have taken on an increasingly important role in integrated urban planning and in 2007, the preparation of an Integrated Urban Development Strategy (IUDS) was made compulsory for cities applying for Structural Funds for urban renewal actions in the EU, and by 2011, the EU had implemented a Reference Framework for European Sustainable Cities that serves to spread integrated urban development approaches with the help of an online tool (BMVBS/DIFU, 2012). This was followed in 2013 by the German Association of Cities advising cities to make increased use of the German instrument of Integrated Strategic Urban Development (DST, 2013). In its position on the New Urban Agenda, the German Government again strongly underlined the need for integrated urban development (BMUB/BMZ, 2015), and the 2016 Pact of Amsterdam also underlines the need for a balanced, sustainable and integrated approach to urban challenges (EU, 2016). The Agenda 2030 also strongly underlines the integrated nature of the SDGs also in SDG 11 on cities (United Nations General Assembly, 2015), and the "Berlin Recommendations for the Cities of Tomorrow" (German Habitat Forum, 2016), again underlines the need for an integrated urban development approach. Out of this environment, in 2011, the Water-Energy-Food (WEF) Nexus approach emerged as a feasible way to instrumentalize integrated urban planning.

This article illustrates how transformative action to achieve the International Agendas (SDGs, Habitat III, Paris Climate Agreement) and finally decarbonize the economy should best start-off within cities using a cross sectoral "Nexus" approach for investment in infrastructure also involving the national level. The method introduced and explained in this article consists of a multi-level and multi-sectoral approach enhancing institutional change and technological, environmentally friendly innovation in parallel. The method consists of "Nexus Training Modules" developed within the German International Cooperation (GIZ) and other instruments to revise the organizational processes for infrastructure planning on city and national level. In short, the method consists of Nexus training for decision makers and support staff, the creation of Nexus Task Forces, screening of infrastructure projects according to Nexus approach criteria, national-local dialogue forums, regional experience sharing events and the implementation of Nexus (pilot) projects as learning by doing exercise. The involvement of academic institutions (universities, etc.) plays an essential role to scale up innovation and create confidence, know-how and sustainability. In this article, special emphasis will be laid on the two essential aspects of the method being the Nexus Training and the involvement of universities.

\section{THE WEF NEXUS APPROACH}

The Nexus of natural resources is not a new concept (ESCAP et al., 2019): as early as 1983, the United Nations University's Food-Energy Nexus Program conceptualized an integrated food-energy systems approach for sustainable development and supported action-oriented, interdisciplinary research that considered biophysical, social, ecological and institutional dimensions (Sachs and Silk, 1990). A series of milestones followed, advancing the Nexus concept and contributing to the dialogue leading to the adoption of the 2030 Agenda for Sustainable Development. The United Nations Conference on Environment and Development (Rio Earth Summit) in 1992 galvanized the sustainable development movement. Representatives from Governments, academia and nongovernmental organizations (NGOs) came together to rethink economic development, find ways to curtail natural resource destruction and pollution and recognize the interrelationships 
between natural resources and growing scarcity. The 2008 World Economic Forum annual meeting assembled the leading public sector, corporate, NGO and academic experts to examine the water crisis issue from different perspectives. The outcome report Water Security: The Water-Food-Energy-Climate Nexus forecast an impending water crisis by 2025 , if society continues on a business-as-usual path of (mis)managing water resources [World Economic Forum Water Initiative (WEFWI), 2009]. The report recommended solutions regarding how to manage the water-energy-food-climate interrelationships and emphasized linkages between water, energy, food and economic growth. In 2011 the World Economic Forum identified the lack of understanding about the nexus as a major economic challenge.

At the landmark Bonn Nexus Conference in 2011, a breakthrough was achieved regarding the term "Nexus," which was presented as a solution to address the limitations of existing approaches (Hoff, 2011), including (ESCAP et al., 2019):

- Individual examination of resources

- Sector-based tools and methods without integration

- Institutions with sectoral mandates

- Micro-economic models focused only on economic flows

- Qualitative environmental models without quantitative approaches.

Building on the growing momentum, the Nexus work of the Food and Agricultural Organization of the United Nations (FAO) and the University of North Carolina Water Institute's "Nexus 2014: Water, Food, Climate and Energy Conference" (with a followup conference in 2018) helped anchor Nexus as an approach within global agendas. The scope of dialogue on Nexus continues to expand and evolve, encompassing urban challenges ranging from waste, mobility and land use to education, health and social equity (ESCAP et al., 2019).

The Nexus approach is nowadays reflected in the term "Green Transformation" and "Green Recovery" (BMZ, 2021): The underlying concept of the EU European Green Deal, a new program/directive of the EU to become the first climate-neutral bloc in the World by 2050, is to improve people's well-being and make Europe more competitive. It is part of the development projects supported by the EU in developing economy countries. The EU calls the "food, water and energy Nexus" the way forward to reach the "green transition." It reflects very well the "green recovery" aiming at a climate-friendly design of economic recovery measures in the wake of the COVID-19 pandemic. The final aim of climate-friendly economic recovery measures is stepping up investments into green infrastructure and the decarbonisation of the energy sector to reach climate change mitigation and adaptation.

\section{NEXUS TRAINING DEVELOPMENT}

In order to transfer Nexus theory into practice, in 20152016 a Nexus training module was designed and implemented by the German International Cooperation (GIZ) Sector Project "Sustainable Development of Metropolitan Regions"
(GIZ/ICLEI, 2014). This training framed the Urban Nexus as a guiding principle for sustainable urban and regional development that facilitates the efficient planning and management of limited resources, following the principles of a pro-poor, inclusive development of cities and metropolitan regions. As a guideline to urban practitioners, the Urban Nexus Development Cycle helps to overcome "silo thinking" and to create a sound framework for inter-sectoral cooperation by providing a strategic design process for collaboratively translating integrated policy and planning objectives into feasible projects, technical solutions and operations. Focusing on local and customized solutions, the Urban Nexus approach includes tools and measures that engage stakeholders in the planning, design, implementation, and monitoring of integrated initiatives. This training was developed primarily for deployment by GIZ staff and consultants in GIZ projects. The target group is envisaged as encompassing all stakeholders relevant and necessary for sustainable urban development.

In 2016, this training was further developed by Dr. Daphne Gondhalekar in collaboration with GIZ, based on a training on integrated urban planning developed in collaboration with Urban Environment (URBEN) Group in 2009. By fusing with the URBEN training approach, the GIZ training content was expanded to a more context-based approach by adding the systematic identification of "Key Nexus Synergy Opportunities" across three or more "sectors" in order to counter "silo thinking," using case study cities to visualize Nexus thinking in a tangible way.

The innovative "Urban Nexus Development Cycle" thus takes cities as a starting point in its approach and consists of five stages that are deployed in an iterative process to jointly develop Nexus solutions:

1. Identify: this stage is used to identify the key assets and urban development challenges of a given city and their interlinkages, areas for increased efficiency and effectiveness in resource uses and service delivery, as well as specific characteristics of local context and available options;

2. Innovate: here, key synergy opportunities across sectors and hotspots requiring urgent attention are highlighted, integrating technical solutions through a combination of natural resources, physical infrastructure and institutional changes; new partnerships should be formed to put each stakeholder's capabilities and resources to best use;

3. Design and Deliver: this stage serves to devise integrated solutions based on the cross-sectoral initiatives identified in the previous stage;

4. Capacitate and Communicate: in this stage, devised solutions are evaluated;

5. Mainstream: here the replicability and scaling-up of devised solutions is discussed.

Depending on the context, this cycle may be repeated several times. These stages are grouped into three modules for the training implementation of typically three to four days duration using the city of training implementation as the case study city, as follows: 


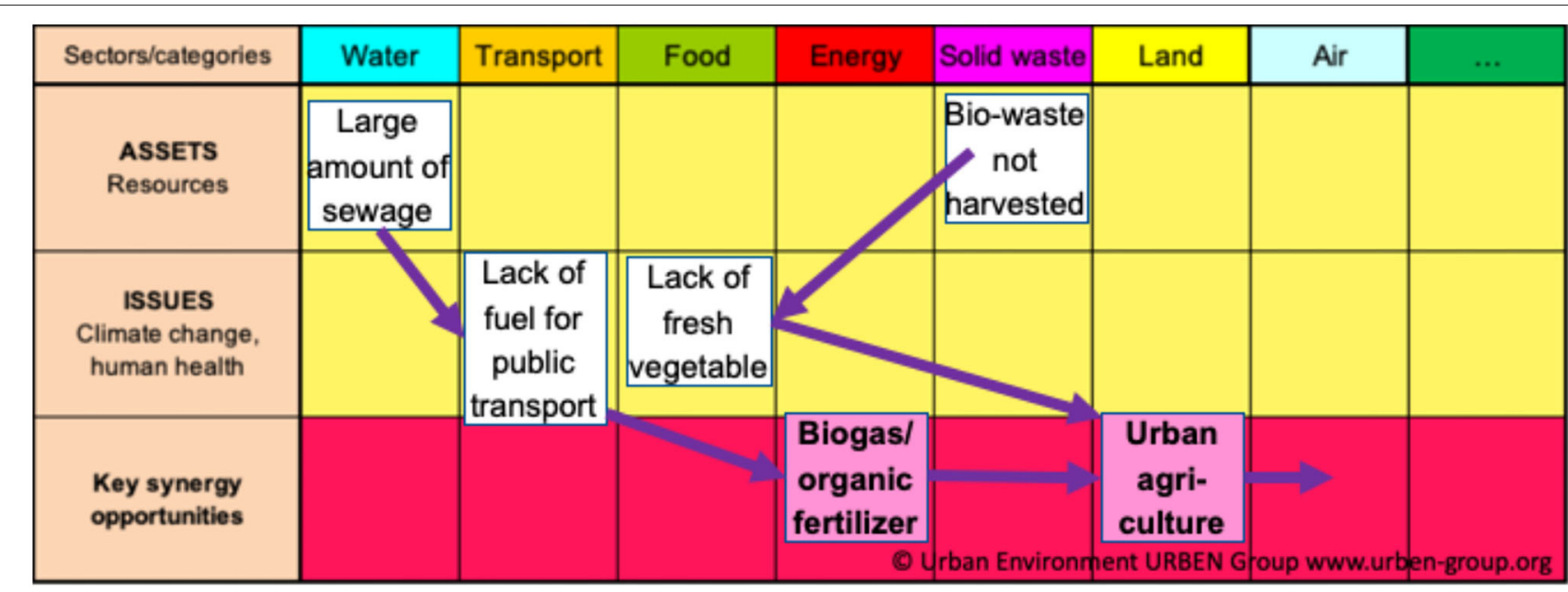

FIGURE 1 | Example of developing Nexus solutions using the Context Assessment Matrix ๑ URBEN.

In Module 1, the training is broadly introduced to the participants before jointly identifying the case study city's key urban development challenges and formulating a joint vision for the year 2030. The origins of the GIZ Urban Nexus Approach and its focus and aims are discussed, such as how it helps to realize opportunities for integrated resource management, i.e., increased policy coherence, accelerated access to resources, creating more with less, minimizing resource wastage, effective use of natural infrastructure, and influencing consumer behavior and everyday practices, and also how it contributes to good governance, green growth, resilient cities, climate change adaptation and mitigation, and solving other pressing issues. The approach is also put into context of the three dimensions of sustainability and key related international development agendas such as the Paris Climate Agreement, SDGs (2030 Agenda), and Habitat III.

This module deals with how to cluster challenges in thematic areas and analyzing how they are interrelated and linked to water, energy and food security. Formulation of the vision is a crucial step as the vision is used to guide the rest of the process and keep the trainers and participants "on track." Each participant is encouraged to consider an individual vision for the case study city before commonalities in the participants' visions are discussed to forge a common vision.

Further, an introduction is given to exemplary applications of the Urban Nexus Approach in other cities and urban regions, focusing on where it has been piloted, particularly in the integrated urban planning aspects, and how the approach has been operationalized within these cases. Finally, Module 1 introduces the five Urban Nexus Development Cycle stages outlined above.

Module 2 combines stages one to four of the Urban Nexus Development Cycle. Its overall key objective is to identify key urban development challenges and potential "Key Nexus Synergy Opportunities" and intervention hotspots, and develop integrated "hard-side" and "soft-side" Urban Nexus solutions to address urban development challenges, which are then checked against their feasibility. In detail, in Stage 1 of the cycle "Identify," participants discuss and analyse the specific case study city, identifying key assets and key issues, and develop a stakeholder map. In particular it is discussed what the key assets and key issues of the case study city are and how these are interlinked, who the key stakeholders in the case study city are and what is their role in relation to these key assets and issues is, and into which sectoral categories and government levels these stakeholders can be organized. To this end, a "Context Assessment Matrix" is deployed, based on a Strengths, Weaknesses, Opportunities and Threats ("SWOT") analysis divided by hypothetical urban "sectors" to visualize cross-sectoral thinking (Figure 1). In Stage 2 "Innovate," participants identify and analyse synergy opportunities with regard to the case study city's assets and issues and discuss key stakeholder coalitions and conflicts. Key hotspots for immediate actions are identified in the case study city, and which of the identified stakeholder coalitions and conflicts are most crucial with regard to identified hotspots.

Stage 3 "Design and Deliver" supports participants to develop, design, and discuss potential integrated urban planning solutions packages to address the case study city's hotspots and analyse the integration and innovation potential of proposed measures. This stage discusses what measures are available to address the case study city's hotspots, what these measures would look like in the urban context, how these measures can be bundled into integrated Urban Nexus solutions packages, and which of these solutions packages with measures best integrates and innovates in an Urban Nexus Approach sense. This stage utilizes a catalog of around 10 Nexus good practice case studies chosen from a broader selection to suit the case study city context. Here the facilitator introduces the good practices by visualizing potential synergies between various measures, a catalog of possible measures and a set of measure cards, and explains how to use these tools in the exercise. With these tools in hand, participants work in groups to transform the "Key Nexus Synergy 


\begin{tabular}{|c|c|c|c|c|c|c|c|c|c|c|}
\hline Hotspot & $\begin{array}{l}\text { Proposed } \\
\text { Measure }\end{array}$ & $\begin{array}{l}\text { Resource } \\
\text { Efficiency }\end{array}$ & $\begin{array}{l}\text { Inclusive- } \\
\text { ness }\end{array}$ & Resilience & Capacities & Costs & Sum & $\begin{array}{l}\text { Average } \\
\text { Points }\end{array}$ & $\begin{array}{l}\text { Level of } \\
\text { Integration }\end{array}$ & Sum \\
\hline \multirow{5}{*}{ A } & & 2 & 1 & 1 & 1 & 2 & 7 & \multirow{3}{*}{5.3} & \multirow{3}{*}{1} & \multirow{3}{*}{6.3} \\
\hline & q & 2 & 1 & 1 & 0 & 2 & 6 & & & \\
\hline & $\mathrm{h}$ & 1 & 1 & 0 & 1 & 0 & 3 & & & \\
\hline & j & 0 & 2 & 0 & 2 & 0 & 4 & \multirow{2}{*}{6} & \multirow{2}{*}{2} & \multirow{2}{*}{8} \\
\hline & k & 1 & 1 & 2 & 2 & 2 & 8 & & & \\
\hline \multirow{4}{*}{ C } & $\mathrm{m}$ & 0 & 2 & 1 & 0 & 2 & 5 & \multirow{4}{*}{5} & \multirow{4}{*}{2} & \multirow{4}{*}{7} \\
\hline & $\mathrm{n}$ & 1 & 2 & 0 & 1 & 1 & 5 & & & \\
\hline & 0 & 1 & 1 & 1 & 2 & 0 & 5 & & & \\
\hline & $p$ & 0 & 0 & 1 & 2 & 2 & 5 & & & \\
\hline
\end{tabular}

2 points $=$ the measure is very supportive towards the objective described in a criterion 1 point $=$ the measure is somewhat supportive towards the objective described in a criterion 0 points $=$ the measure is not supportive towards the objective described in a criterion

FIGURE 2 | Example of a feasibility evaluation for Nexus solution packages ๑ GIZ.

Opportunities" previously identified into potential solutions to address the case study city's hotspots.

In Stage 4 "Capacitate and Communicate," participants then evaluate the feasibility of identified solutions packages for the case study city and discuss the role of key stakeholders in enabling the implementation of proposed measures. A scoring system (Figure 2) is used to rank the different groups' solution packages in terms of feasibility of implementation giving scores of 0,1 or 2 ( 0 being least and 2 most implementable), whereby the solution with the highest score is taken to be the most implementable. This exercise aims to reveal major implementation hurdles, capacity needs, and related options to address these.

Finally, Module 3 prepares the implementation of Urban Nexus Solutions. Its key objective is to check the feasibility of these identified integrated solutions and discuss first steps for their implementation, representing Stage 5 "Mainstream" of the Urban Nexus Development Cycle. This module focuses on useful entry points for integration and innovation in urban development, success criteria for Urban Nexus projects, checks how far proposed Urban Nexus solutions match with the key urban development challenges and 2030 visions that participants formulated in Module 1. It moreover discusses how visions can become reality and how Urban Nexus solutions can be mainstreamed. The next steps take forward the Urban Nexus Approach to the implementation/operationalization stage formulating a joint Action Plan.

This training was deployed in several instances including through the GIZ Connective Cities Program in the Isipingo neighborhood of the City of Durban, South Africa, in 2016 in collaboration with the Municipality of eThikwini, and in collaboration with the project "Integrated resource management in Asian Cities: the Urban Nexus" as described in the next chapter.

\section{TRAINING DEPLOYMENT IN GIZ URBAN NEXUS PROJECT IN ASIA}

In the Asia-Pacific region, GIZ in collaboration with the United Nations Economic and Social Commission for Asia and the Pacific (ESCAP) in collaboration with ICLEI (Local Governments for Sustainability) (ESCAP et al., 2019) envisaged to introduce holistic, integrated resource management for Asian cities through the joint project "Integrated resource management in Asian Cities: the Urban Nexus," financed by the German Federal Ministry for Economic Cooperation and Development (BMZ) and implemented by GIZ. This project was implemented in two phases between 2013 and 2019 and sought to promote and institutionalize the Urban Nexus approach through the provision of Nexus training and related technical advice to municipal administrations for the design, planning and implementation of practical nexus initiatives in up to 12 selected Asian cities in seven countries (China, India, Indonesia, Mongolia, Philippines, Thailand and Viet Nam).

In this context, the GIZ Urban Nexus project elaborated and implemented a complementary, face-to-face, interactive training program on the Urban Nexus approach, based on the Urban Nexus Training described in the previous section. It is in particular adjusted to the situation in Asian cities and countries and their institutional and technical environment. This type of training is aimed at communicating and anchoring the Urban Nexus planning and management approach in cities and countries. The Urban Nexus training takes into account relevant global agendas, such as the 2030 Agenda for Sustainable Development, the New Urban Agenda (Habitat III) and the Paris Climate Agreement, and offers dynamic and new interactive formats for participants to learn about and reflect on the relevant issues of the Urban Nexus approach by analyzing infrastructure problems of their city and country. 
The main target groups of this training are government staff (local, provincial, and national), training institutes and universities (academia) involved with developing urban infrastructure projects, in addition to private and civil society entities relevant to implementing the projects.

As the GIZ Urban Nexus Project has taken a six-step approach to promote the Urban Nexus in the Asia-Pacific region this is also reflected in the Urban Nexus Training modules:

- Identifying the most urgent infrastructure deficits within the Nexus partner cities together with the city representatives.

- Elaborating feasible cross-sectoral infrastructure projects in the Nexus partner cities with broad stakeholder involvement.

- Developing capacities of relevant actors in cross-sectoral planning through the elaboration of infrastructure projects with cross-sectoral linkages and training workshops.

- Supporting a multi-level governance approach by bringing actors from the national and the local level together (nationallocal dialog forums, vertical integration).

- Promoting intercommunal cooperation (horizontal cooperation) with respective institutional structures for the implementation of infrastructure activities requiring clustering to solve the problems (e.g., watershed management, solid waste management, etc.) in particular considering economies of scale.

- Facilitating the exchange of experience, peer-to-peer learning and the upscaling of the Urban Nexus through regional dialogues and mutual visiting tours throughout Asia.

- Promoting the Urban Nexus approach through national and regional multipliers who introduce the concept to their networks.

As a result of these measures, the Urban Nexus partner cities and countries have become increasingly interested in applying integrated approaches. However, the necessary policies are only formulated hesitantly.

This training concept combines integrated resource management ("Nexus") with a systemic approach to analyzing complex challenges as well as design thinking on the background of the Global Agendas. The innovation approach Design Thinking provides the mindset and methods to develop creative and innovative solutions for complex problems. It fosters an agile culture of learning and working that helps managing digital transformation. Multidisciplinary teams work in a flexible environment and apply an iterative process to develop humancentered products, services or business models. The first day of the training workshop focuses on a deeper understanding of the Nexus approach by analyzing major challenges on national level. The second day focuses on the development of possible multi-sectoral, interinstitutional, coordinated solutions based on key elements of the Design Thinking method.

During the training, participants are working in groups, each group addressing one of the major ecological, economic and social challenges identified prior to the training workshop. The trainers emphasize the link to the Urban Nexus and integrative solution approaches at all times. Each phase of the training is introduced by a short, visualized input on the tools and methods used. Relevant technical state-of-the art and governance background information to integrated resource management are provided complementing the training and setting the framework.

Based on the modular concept of the Urban Nexus Training, the training manual uses a two-day training as a basis. However, it can be conducted in three alternative scenarios according to the target-groups:

- 0.5 day (executive briefing);

- 2.0 day (basic version);

- 2.5 day (extended version).

The executive briefing version for a half day training seminar aims at raising the awareness of the respective target group rather than conveying in-depth knowledge on the topic. This set-up consists basically in the introductory presentations developed for each module and interactive brainstorming respectively discussion rounds to ensure that the main components of the Urban Nexus approach are explained and the basis for follow up activities is ensured.

The 1- and 2.5-days versions allow for a training approach with several interactive exercises. Especially with the extended version participants are able to initiate concrete exercises relevant to the respective situation in their country.

The assessment of participant's training needs is crucial to developing a tailor-made training programme catering to their specific information requests. Therefore, the manual contains a set of "alternative exercise" options, which can be used according to the participants' needs.

The training material consists of Hand-outs to guide participants through the exercises and case studies of each training module. The Trainer's Manual, addressed to the trainers, is meant to offer them a structured guideline on how to implement the interactive exercises.

\section{NEXUS IN PRACTICE: GIZ NEXUS PROJECT IN ASIA}

This section concentrates on Nexus elaborations and experiences-seen within the context of a circular economy which can also be called "green transition"-gained from developing economies and emerging markets in Asia within the project "Integrated Resource Management in Asian Cities: the Urban Nexus."

The project targeted countries in South and South-East Asia and East and North-East Asia with a relatively large and growing resource footprint and rapid urbanization, and thus needed to adopt integrated approaches to sustainably manage natural resources, particularly energy, water and food/land. The Government of Germany, supported by GIZ, selected target cities that generally displayed strong local leadership, an interest and willingness to adopt innovative infrastructure approaches, including structural governance changes to solve environmental and health challenges, and an inclination to work across sectors with a broad range of stakeholders.

The project assisted 12 cities (Rizhao, Weifang/China, Nagpur, Rajkot/India, Pekanbaru, Tanjungpinang/Indonesia, Ulanbaatar/Mongolia, Naga City, Santa Rosa/Philippines, 


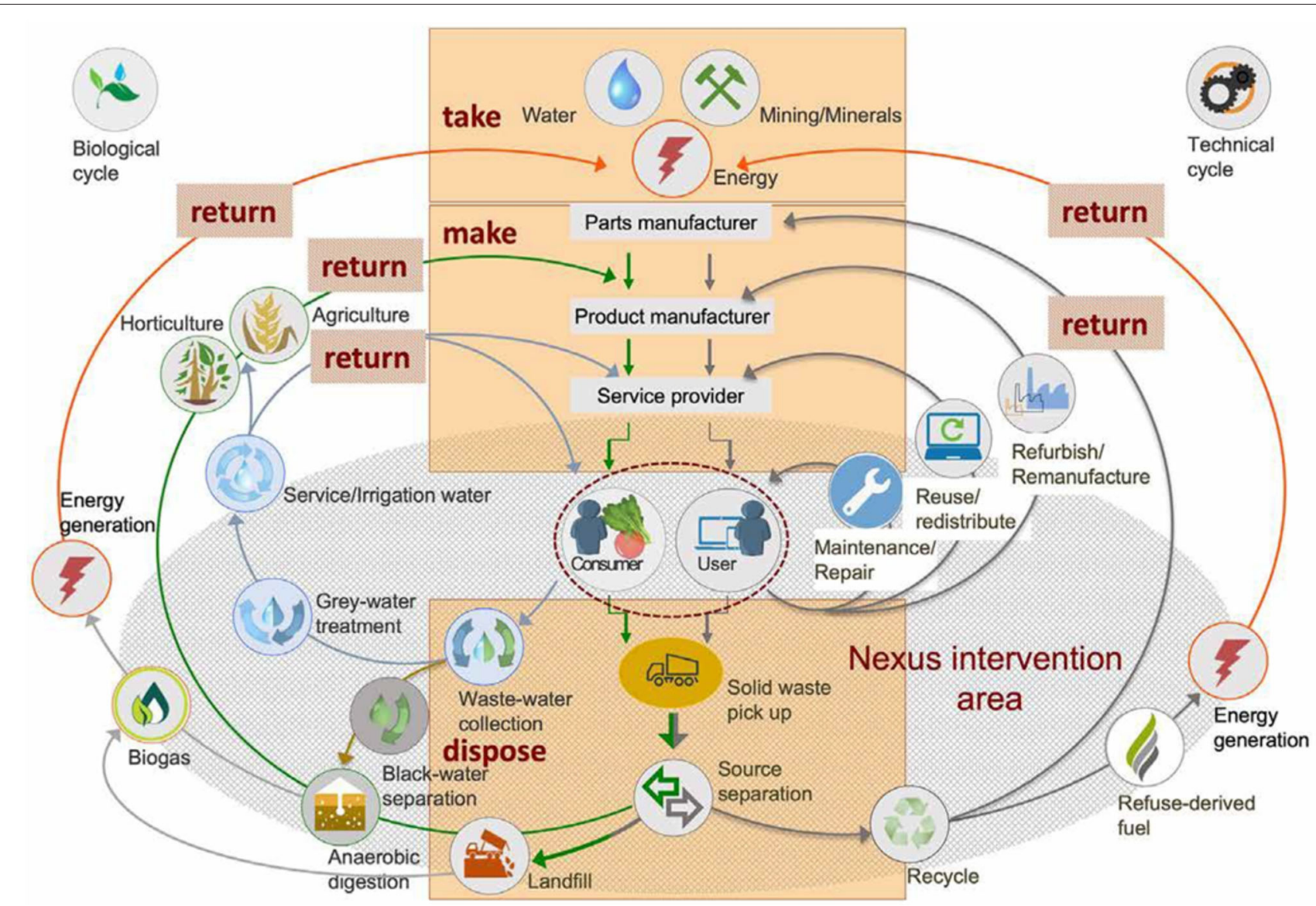

FIGURE 3 | Circular economy with energy and mass flow cycles (GIZ, 2014). Source: ESCAP et al. (2019).

Chiangmai, Korat/Thailand and Da Nang/Vietnam) in seven countries (China, India, Indonesia, Mongolia, Philippines, Thailand and Vietnam) with developing and advancing integrated approaches to natural resource management, including mainstreaming the Nexus approach into strategies for the implementation of key global agendas.

The project aimed at creating resilient cities through Nexus training, the creation of Nexus Task Forces, screening of infrastructure projects according to Nexus approach criteria, national-local dialogue forums, regional experience sharing events and the implementation of Nexus (pilot) projects concentrating technically on innovative solutions for:

- Improved water management

- Waste water reuse

- Waste to energy

- Energy efficiency of buildings, renewable energy applications.

Discussions and recommendations on the improvement of respective framework conditions was naturally an essential part of the effort to make the introduction of innovative, cross-sectoral State-of-the-Art technologies economically and financially viable and feasible.
The technologies were embedded in the Global Agendas-2030 Agenda for Sustainable Development, the New Urban Agenda (Habitat III) and the Paris Climate Agreementand the vision of a circular economy (see below). Moreover, people-centered development ("leave no-one behind") and empowerment of cities were the guiding principles.

Figure 3 explains the circular economy as "a model of production and consumption, which involves sharing, leasing, reusing, repairing, refurbishing and recycling existing materials and products as long as possible" that aims at tackling global challenges like climate change, biodiversity loss, waste, and pollution. It is defined in contradistinction to the traditional linear economy. The Nexus approach aiming at resource efficiency in the context of "take, make, return" is embedded in the vision of the circular economy. A separation into the different mass flow cycles such as e.g., black and gray water helps to recycle the scarce resources and to "close the loop." The circular economy considers a "Biological" and a "Technical" cycle, distinguishing between organic and inorganic material.

Strategically, the project focused on three core elements: (1) Nexus training, (2) Elaboration of Nexus infrastructure projects on the basis of pre- and feasibility studies demonstrating in an exemplary way how to integrate the nexus approach 


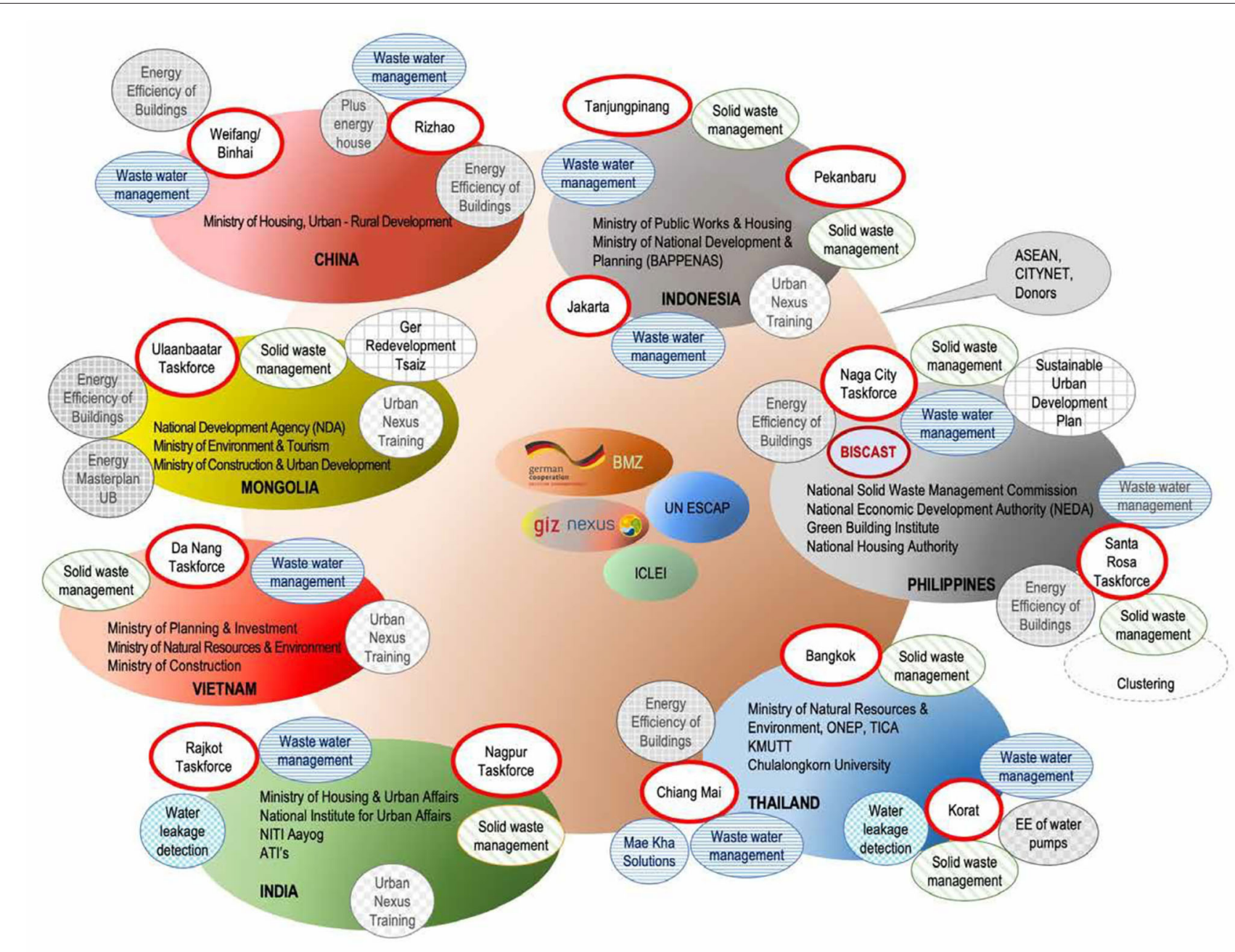

FIGURE 4 | Project cities and Urban Nexus Measures (GIZ). Source: ESCAP et al. (2019).

into urban planning and development processes for improving urban services. (3) Regional experience sharing on integrated resource management through regular and face-to-face networking, workshops, peer-to-peer learning and technical training to promote and roll-out the Nexus approach.

Wastewater and solid waste management were foci of the project in addition to water, energy and food/land, as project cities often identified these as their most urgent problems. Wastewater and waste were viewed as resources to close the loop within a circular economy approach. A multilevel approach was applied, with the local level as the starting point. Nexus initiatives supported municipal administrations with analyzing the cities' problems and identifying cross-sectoral solutions to address them also connecting with private sector enterprises. At the meso level, city associations, universities, training institutions and civil society organizations were central actors. At the macro level, national ministries and agencies were engaged to support advancement of the Nexus concept (ESCAP et al., 2019).
Continuous capacity building primarily conceived as on-jobtraining as well as tailor-made Nexus training sessions were part of the effort.

Figure 4 is an organizational chart providing an overview of the different countries, actors and topics dealt with within the framework on the "Integrated Resource Management in Asian Cities Project" implemented by GIZ in collaboration with UNESCAP and ICLEI in Asia and financed by the German Federal Ministry for Economic Cooperation and Development (BMZ).

\section{IMPACT}

As a result of this project, altogether more than 55 innovative cross-sectoral (pilot) state-of-the art investment projects amounting to US $\$ 600$ million have been jointly studied and elaborated, some still in the pipeline for financing. Several Nexus pilot investment projects costing < US \$1 million have been implemented and financed by the project cities, resulting in improvements in residents' lives and cost savings 
for the municipalities. Dialogues, particularly between local and national levels of government, have laid the groundwork to introduce the required policy shifts needed to advance integrated resource management in cities, including to mainstream the Nexus approach into national initiatives for the implementation of the 2030 Agenda for Sustainable Development, the New Urban Agenda, and the Paris Climate Agreement. Achieving national targets and global agenda commitments demands coordination and coherence with involved stakeholders from governments, academic institutions, private sectors, and civil societies, working together to ensure optimization of resource integration (ESCAP et al., 2019).

Technologies such as vacuum sewer wastewater collection, decentralized treatment facilities as well as Maximum Yield Technology (MYT) for solid waste management not only consider the recovery and reuse of valuable resources, but also the land-use dimension. "Land is gold," hence innovative technologies improving the resilience of cities must economize on land consumption as urban centers are increasingly running out of land. The introduced technologies reflect decentralized approaches and reuse concepts. However, being modular systems, they can also be integrated into existing grid systems. To scale up innovative green technical solutions, financial incentive mechanisms including cost recovery and consumption-oriented tariffs must be introduced.

\section{LESSONS LEARNT FROM NEXUS IN PRACTICE}

The ideas, partnerships, networks, and activities that have been initiated through Urban Nexus offer great potential for cities to take forward integrated approaches and develop innovative policies to reduce resource consumption. It is of utmost importance to revise regulatory frameworks and introduce incentivizing instruments to guide resource efficient and hence sustainable urban development in the context of a circular economy. Mainstreaming the Urban Nexus approach can lead to entrepreneurial solutions to resource management throughout Africa, Asia and the Pacific, Latin America, and the Middle East.

Local administrators and specialists are the target audience for applying the Urban Nexus approach, as they are the key actors involved with applying cross-sectoral infrastructure planning and management projects.

The Urban Nexus evolves from initiating activities in cities and increasing national-level engagement to collaborating with many sectors and groups, including youth and academia, to cultivate a mindset of lifelong learning needed to advance sustainable development. Many training institutes have already embraced transdisciplinary, integrated approaches in their curricula and teaching. Today's youth are the leaders of tomorrow, and students, teachers and schools are natural multipliers needed to mainstream sustainable development values.

Managing resources requires good spatial mapping and integrative and well-organized spatial planning as well as institutional coordination and political will. Planners at the local and subnational levels are starting to integrate Nexus thinking into their comprehensive land-use plans. This dimension addresses strengthening urban-rural relationships, important to developing integrated solutions and promoting resilience with such measures as peri-urban agriculture and sustainable land-use planning. Effectively and efficiently addressing water, energy and food/land security involves understanding urban-rural linkages, as resources cross scales and boundaries, and cities' increasing consumption demands require drawing from supplies in the rural hinterlands.

However, cross-sectoral and planning ministries play a key role in promoting the Nexus approach as well as the agencies and ministries mandated to coordinate the Sustainable Development Goals and the implementation in each country of nationally determined contributions (NDC) under UNFCCC. Apart from planning and finance ministries, the ministries of natural resources and environment also have significant cross-sectoral functions, although they often lack power.

For cities it is important to consider introducing "Nexus" screening of investment projects to ensure that they have been planned in a cross-sectoral manner, which will support more sustainable infrastructure projects. Although urban planning is per definition a cross-sectoral task, cross-sectoral coordination needs to be further enhanced.

With much of the projected infrastructure in developing economy countries and their cities still to be built, the Urban Nexus approach provides an opportunity to create liveable, healthy, prosperous, and resource-efficient cities, while also contributing to global development agendas. The 2030 Agenda for Sustainable Development requires integrated approaches that cannot be reached by the national level of Government alone. Subnational and local involvement is key, and the Nexus approach at its core involves horizontal and vertical integration. Improved coordination and collaboration that is based on the untapped interdependencies between the water, energy and food/land sectors can result in substantial resource and financial benefits, making the business case for Nexus projects.

\section{CONCLUSIONS}

The dialogue on the water, energy and food/land Nexus continues to expand and evolve as the Nexus approach brings together stakeholders to increase the knowledge base, support decisionmaking and encourage discussion to identify integrated issues and solutions (ESCAP et al., 2019). More work has to be done, as there are still a large number of challenges when transforming the Nexus approach (theory) into practice and back again into targeted teaching to improve employability of young professionals in Nexus jobs that do not yet exist but are at the brink of coming into being and are most urgently needed to enable "climate neutral" or "zero carbon" urban development.

In this context, the Nexus Training as essential part of the method to introduce the Nexus approach has to be intensified, broadened and further rolled out. Training institutes and in particular universities should take up this approach in their training courses and their extension activities.

Within the Nexus Training, the following topics play an essential role and should be addressed even more in the Nexus training modules: Additional practical training units (hands-on 
approach) might have to be incorporated with more learning by doing "in situ" in respective locations within cities.

The following aspects need a strong emphasis within the Nexus training:

Cities have to be given "a voice." They have to be empowered through a decentralization of the administrative structures of the country following the subsidiarity principle: decisions should be taken at the lowest level possible closest to the citizens so that the concerns of the latter are understood. Moreover, cities need finance they can dispose of, they have to be mandated to access the banks to obtain loans and the need capacity building and human resource development (ESCAP et al., 2019).

Cities have to follow a participatory approach involving the citizens in all decisions concerning the city, the infrastructure planning and the respective financial planning. A structured and organized city's participation process has to be established, monitored, evaluated, adjusted and followed up. Only then can cities become resilient.

Framework conditions at local as well as at national level have to be thoroughly analyzed to identify their potential to incentivise innovative, cross sectoral solutions. In many cases they will have to be revised to allow for Nexus approaches to enhance sustainable infrastructure solutions and participation processes.

Innovative Nexus solution have to be economically feasible in order to attract private investment and hence to be implemented. Respective cost-covering and consumption-oriented tariffs and fees are essential aspects to allow for the introduction of new technologies and resource-efficient and resource-saving solutions. For vulnerable groups subsidized schemes might be a solution although it is difficult to handle them targetgroup oriented.

The Nexus approach should start off by piloting innovative cross-sectoral technological solutions (smaller infrastructure projects in water and wastewater management, solid waste management, energy efficiency of building) in collaboration with training institutes and universities ("hardware" aspect to create resilient cities)_-"seeing is believing."

A regular and systematic Nexus screening for investment projects should be introduced at local as well as at national level to ensure that projects have been planned in a cross sectoral manner in order to achieve sustainability. Moreover, it is essential to consider capital expenditure as well as operation and maintenance cost during the planning process of infrastructure investment projects to reach sustainability.

Existing procurement rules and regulations have to be thoroughly analyzed and possibly revised in order to allow for green procurement and hence sustainable, long-lasting solutions.

In order to promote the Nexus approach efforts to collaborate in a targeted way with educational institutions, universities, research and training providers have to be intensified. Training and capacity-building, often in partnership with training institutes and/or academia, at all levels of institutions, can help change "business as usual" approaches to urban development and adopt an integrated approach to improve resource efficiency and overall quality (ESCAP et al., 2019).

With much of the projected infrastructure in African, Asian, Latin American and Middle Eastern cities still to be built, the Urban Nexus approach provides an opportunity to create liveable, healthy, prosperous, and resource-efficient cities, while also contributing to global development agendas. The 2030 Agenda for Sustainable Development requires integrated approaches that cannot be reached by the national level of government alone. Sub-national and local involvement is key, and the Nexus approach at its core involves horizontal and vertical integration. Improved coordination and collaboration that is based on the untapped interdependencies between the water, energy and food/land sectors can result in substantial resource and financial benefits, making the business case for Nexus projects.

As "rethinking" is a matter of mindset, thus the Urban Nexus approach, considering cross-sectoral thinking, has to start off in the education sector applying different pedagogical tools to be integrated into existing curricula. All training levels and institutions (primary, secondary, technical-vocational/TVET and university levels) need practical as well as theoretical training in cross-sectoral thinking and its application. At university level, it will be of utmost importance to link more closely the training of urban planners and architects, and the different engineering specializations such as sanitary, electrical, environmental/climate, civil engineering etc. enabling graduates to think "out of the box." The Nexus Training established at TUM master level course is a best practice example in enabling multisectoral engineers, urban planners and architects, and natural resource managers, to be trained in developing more sustainable infrastructural approaches and solutions. These professionals are the ones to elaborate the Terms of References for tenders and evaluate the tenders as well as to supervise constructions works. Hence a revision of their professional proceedings and performance will trigger the required change of paradigms. Respective tailormade revised curricula at primary, secondary and TVET level can further pave the way for development of innovative integrated, resource efficient solutions. The experiences of the Urban Nexus approach of GIZ in South and Southeast Asia clearly proved that the involvement of the tertiary level, i.e., academia, is essential to reach sustainable cross-sectoral, innovative resource efficient solutions.

However, the change of paradigms in relation to training in engineering and urban planning has to include "soft skills" such as tools for mediating and guiding stakeholder processes including conflict resolution, complex interdisciplinary project management, and knowledge of the "boundary conditions" including framework regulations, standards, incentive mechanisms, organizational aspects as well as feasible business models in order to be able to forge innovation. A purely technological approach cannot be the solution!

\section{DATA AVAILABILITY STATEMENT}

The original contributions presented in the study are included in the article/supplementary material, further inquiries can be directed to the corresponding author.

\section{AUTHOR CONTRIBUTIONS}

For this study, DG and RE were both responsible for the study conceptualization and co-authoring of the manuscript. RE 
contributed all data pertaining to the project Integrated Resource Management in Asian Cities: The Urban Nexus. Both authors have read and agreed to the published version of the manuscript.

\section{FUNDING}

A part of this work was conducted as a consultancy to the Sector Project Sustainable Development of Metropolitan Regions, GIZ, in 2016.

\section{ACKNOWLEDGMENTS}

Part of the manuscript has been released within The Urban Nexus, Integrating Resources for Sustainable Cities, United Nations Economic and Social Commission for Asia and the Pacific (ESCAP), Deutsche Gesellschaft für Internationale

\section{REFERENCES}

BMUB/BMZ (2015). Habitat III and the New Urban Agenda: The Position of the German Government.

BMVBS/DIFU (2012). 5 Years After the LEIPZIG CHARTER - Integrated Urban Development as a Prerequisite for a Sustainable City: Integrated Urban Development in the EU Member States and Its Candidate Countries. Berlin: Germany.

BMZ (2021). BMZ supports Green Recovery Worldwide.

DST (2013). Integrated Urban Development Planning and Urban Development Management - Strategies and Instruments for Sustainable Urban Development Position Paper by the German Association of Cities Integrated Urban Development Planning. Berlin: German Association of Cities

ESCAP, GIZ, ICLEI- Local Governments for Sustainability (2019). The Urban Nexus: Integrating Resources for Sustainable Cities. Available online at: https://www.unescap.org/sites/default/files/UrbanNexusPublication_Web. pdf (accessed December 03, 2021).

EU (2011). Cities of tomorrow: Challenges, Visions, Ways Forwards. Luxembourg: European Commission.

EU (2016). Urban Agenda for the EU: Pact of Amsterdam. Amsterdam: European Commission.

German Habitat Forum (2016). Berlin Recommendations for the Cities of Tomorrow. Berlin: German Habitat Forum.

GIZ (2014). GIZ Urban Nexus Project.

GIZ/ICLEI (2014). Operationalizing the Urban NEXUS: Towards Resources Efficient and Integrated Cities and Regions. Eschborn: GIZ; ICLEI.

Hoff, H. (2011). "Understanding the nexus," in Background Paper for the Bonn 2011 Conference: The Water, Energy and Food Security Nexus (Stockholm: Stockholm Environment Institute). 1-52.

Mumford, E. (2000). The CIAM Discourse on Urbanism, 1928-1960. Boston: MIT Press.

Sachs, I., and Silk, D. (1990). Food and Energy: Strategies for Sustainable Development. Tokyo: United Nations University Press.

UN (2021). Goal 11: Make Cities Inclusive, Safe, Resilient and Sustainable.

United Nations (2016). World Needs 'New Vision for Urbanization,' Says UN Chief. Available online at: http://www.un.org/apps/news/story.asp?NewsID=53669\#. VxiuamNDWPq (accessed December 03, 2021).
Zusammenarbeit (GIZ) GmbH and Local Governments for Sustainability (ICLEI) Thailand, 2019. RE, author of part of the manuscript, has been a contributing author to the ESCAP Brochure. The ESCAP Report mainly reflects the outcome and lessons learnt on the project Integrated Resource Management in Asian Cities: the Urban Nexus, financed by the German Federal Ministry of Economic Cooperation and Development (BMZ) and implemented by GIZ in collaboration with ESCAP, ICLEI and the partner cities and Countries mentioned above. RE has been the Project Director on behalf of GIZ for the Urban Nexus Project. The authors gratefully acknowledge Carmen Vogt and Katrin Eisenbeiss, GIZ Sector Project Sustainable Development of Metropolitan Regions, and the support of ICLEI, particularly Emani Kumar and Ritu Thakur, and of UN ESCAP, particularly Stefanos Fotiou, Curt Garrigan and Kyungkoo (Philip) Kang in implementing the project Integrated Resource Management in Asian Cities: the Urban Nexus.

United Nations General Assembly (2015). Transforming Our World: The 2030 Agenda for Sustainable Development. Available online at: https://sdgs.un.org/ 2030agenda (accessed December 03, 2021).

World Bank (2020). Urban Development. Understanding Poverty Topics Urban Development. Available online at: https://www.worldbank. org/en/topic/urbandevelopment/overview (accessed December 03, 2021).

World Bank (2021). Climate Change. Available online at: https://www. worldbank.org/en/topic/climatechange/overview (accessed December 03, 2021).

World Economic Forum Water Initiative (WEFWI) (2009). Water Security: The Water-Food-Energy-Climate Nexus. Washington, DC: Island Press. Available online at: https://www3.weforum.org/docs/WEF_WI_WaterSecurity_ WaterFoodEnergyClimateNexus_2011.pdf (accessed December 03, 2021).

Conflict of Interest: RE is employed by the company German International Cooperation (GIZ).

The remaining author declares that the research was conducted in the absence of any commercial or financial relationships that could be construed as a potential conflict of interest.

Publisher's Note: All claims expressed in this article are solely those of the authors and do not necessarily represent those of their affiliated organizations, or those of the publisher, the editors and the reviewers. Any product that may be evaluated in this article, or claim that may be made by its manufacturer, is not guaranteed or endorsed by the publisher.

Copyright (C) 2021 Gondhalekar and Erlbeck. This is an open-access article distributed under the terms of the Creative Commons Attribution License (CC BY). The use, distribution or reproduction in other forums is permitted, provided the original author(s) and the copyright owner(s) are credited and that the original publication in this journal is cited, in accordance with accepted academic practice. No use, distribution or reproduction is permitted which does not comply with these terms. 